\title{
ECONOMIC EVALUATION OF THE MECHANISMS OF ATTRACTING CORPORATIZATION-FOCUSED INVESTMENTS
}

\begin{abstract}
The modern interpretation of the investment concept is analyzed. The modern methods of investments economic evaluation are presented. The nature of investments-attracting mechanisms is defined. A method of investments-attracting mechanisms economic evaluation is proposed.

Key words: investments, investor, investmentsattracting mechanisms, economic evaluation, method of economic evaluation of investments-attracting mechanisms.
\end{abstract}

Materials and methods. Due to transformation processes occurring in the economy there appeared a new interpretation of the investment concept. Thus, the analysis of the recent research works $[1,2,3]$ showed that the scientists provide wider interpretation of the concept of investment. Investments are considered to be any item of tangible or intangible property that is invested by the subject investment activities to achieve certain goals. A new interpretation of the nature of investments requires new ways of evaluating investment activities.

Research into this issue is carried out in many directions. One of the most common ones is based on the use of economic-mathematical methods for economic evaluation of investments. Such researchers as Yes, Lewis, Lipsitz, Golderberger [4] suggest that scientific research in this direction be differentiated into two branches: linear and non-linear dynamics. Both scientific paradigms are competitive, though recently preference has been given to non-linear methods of dynamics analysis. These researchers identify two groups of methods that are used within the paradigm of nonlinear dynamics: fractal analysis and chaos theory. A fractal, as defined by Lewis, Lipsitz, Golderberger, is a structural concept based on a wide range of objects of various geometries presented in a certain sequence. The concept of a fractal is widely considered by Abboud, Berenfeld and Sadeh [5]. The concept of "chaos" is treated by these scientists, following the works of Mandelbrot [6], as the unpredictable behavior of a variable being researched.
The chaos theory has become widely used in the models of economic growth dynamics. Nonlinear mathematical methods were first applied in economics by Frisch, Lundberg and Samuelson [7, p. 78]. These scientists used differential and recurrence equations to explain the dynamics of economic processes.

The mathematical tools proposed by Frisch, Lundberg and Semuelson appeared to be insufficient for solving certain problems being inherent for economic processes. Such problems seemed to be solvable only by using the generalized Semuelson model. This has been proven and put into practice by Hiks and Goodwin [7, p. 79], who used nonlinear regression to justify their own understanding of mathematical interdependencies characteristic for the elements of economic systems.

Prediction of chaotic dynamics of economic processes is an extremely difficult problem, the solution of which requires preliminary determination of the mathematical models that can simulate the chaotic dynamics. The problem was first studied by Baumol \& Quandt [8] and Philips $[9,10]$. As a result, Baumol and Benhabib proposed the recurrence equation that could be used for modeling the chaotic behavior of certain economic processes.

The use of the chaos theory was also actively studied by Guckenheimer and Holmes [11], Grandmount [12, 13], Arrowsmith [14] and others. Boldrin and Woodford [15], Hommes [16], Medio [17, 18], Day [19] and Rosser [20] have greatly expanded the application of the chaos theory in economics.

The theory of fractals has not been applied in economics as widely as the chaos theory so far, though some works in this direction already exist. Among those dealing with the issue there are Mantegna, and Stanley [21]; Gao, Hu, Tung, Cao [22]; Michel [23] and others.

Investments can be attracted by using investments-attracting mechanisms. Thus, in $[24,25]$, the nature of the concept is defined and the expediency of doing research into the issues of 


\section{N. H. Heorhiady, O. Ye. Fedorcha}

economic evaluation mechanisms is substantiated. Given the above and the fact that the most common mechanisms to attract investments are those focused on incorporation, we have chosen proposing a method of economic evaluation of mechanisms to attract investment to the company as the goal of our study.

Results. To present this method let us assume that in the capital market there is one investor and there are several companies (for example, four) whose shares are presented on the stock market. Selection of such simplified conditions can be compared with the "ideal gas" in physics. The purpose of this approach is to analyze of ability of each company's mechanism to attract investments from this assumed investor. Let us also assume that for various reasons all the companies do not pay dividends and the future investor's income will be formed only due to changes in the market price of the shares purchased by him. The investor can make both direct and portfolio investments.

Let us start presenting this method by providing market prices for the shares of the four assumed companies, they being companies A, B, C, D (Table 1).

Table 1

The shares market prices of four A, B, C, D companies

\begin{tabular}{|c|c|c|c|c|c|c|c|c|c|}
\hline Date & $A$ & $B$ & $C$ & $D$ & Date & $A$ & $B$ & $C$ & $D$ \\
\hline 30.09 .2014 & 9.75 & 117.53 & 14.79 & 19.36 & 31.08 .2014 & 10.32 & 117.21 & 17.43 & 19.59 \\
\hline 29.09 .2014 & 9.51 & 117.52 & 15.11 & 19.56 & 30.08 .2014 & 10.31 & 116.89 & 17.31 & 19.39 \\
\hline 28.09 .2014 & 9.52 & 11.65 & 16.33 & 19.73 & 29.08 .2014 & 10.3 & 117.74 & 17.43 & 19.5 \\
\hline 27.09 .2014 & 9.41 & 117.87 & 16.2 & 19.53 & 28.08 .2014 & 10.05 & 117.93 & 17.42 & 19.59 \\
\hline 26.09 .2014 & 9.66 & 118.25 & 16.41 & 19.86 & 27.08 .2014 & 10.05 & 117.24 & 17.21 & 19.26 \\
\hline 25.09 .2014 & 9.92 & 118.25 & 16.17 & 19.71 & 26.08 .2014 & 10.22 & 116.76 & 17.17 & 19.22 \\
\hline 24.09 .2014 & 9.89 & 119.01 & 16.36 & 19.67 & 25.08 .2014 & 10.28 & 117.63 & 17.09 & 19.17 \\
\hline 23.09.2014 & 10.26 & 118.76 & 16.65 & 19.66 & 24.08 .2014 & 10.37 & 116.68 & 16.82 & 18.88 \\
\hline 22.09 .2014 & 10.17 & 119.43 & 16.58 & 19.6 & 23.08 .2014 & 10.42 & 116.61 & 16.98 & 19.1 \\
\hline 21.09 .2014 & 10.02 & 117.35 & 16.53 & 19.54 & 22.08 .2014 & 10.38 & 119.03 & 16.87 & 19.21 \\
\hline 20.09 .2014 & 9.99 & 117.59 & 16.52 & 19.77 & 21.08 .2014 & 10.09 & 118.12 & 17.02 & 19.58 \\
\hline 19.09 .2014 & 9.86 & 117.16 & 16.47 & 19.59 & 20.08 .2014 & 10.05 & 117.59 & 16.81 & 19.63 \\
\hline 18.09.2014 & 9.98 & 117.11 & 16.59 & 19.63 & 19.08 .2014 & 9.96 & 117.99 & 17.02 & 19.66 \\
\hline 17.09 .2014 & 10 & 116.37 & 16.66 & 19.65 & 18.08 .2014 & 10.02 & 120.04 & 17.46 & 19.97 \\
\hline 16.09 .2014 & 10.03 & 116.49 & 16.63 & 19.64 & 17.08 .2014 & 10.09 & 120.58 & 17.57 & 19.93 \\
\hline 15.09 .2014 & 10.09 & 115.02 & 16.63 & 19.38 & 16.08 .2014 & 10.13 & 120.58 & 17.64 & 20.19 \\
\hline 14.09 .2014 & 10.12 & 116.04 & 16.8 & 19.57 & 15.08 .2014 & 10.53 & 119.63 & 17.62 & 19.44 \\
\hline 13.09 .2014 & 10.08 & 116.39 & 17.14 & 19.5 & 14.08 .2014 & 10.66 & 119.38 & 17.84 & 19.6 \\
\hline 12.09 .2014 & 10.06 & 116.05 & 17.27 & 19.5 & 13.08 .2014 & 10.39 & 119.43 & 17.78 & 19.31 \\
\hline 11.09.2014 & 9.9 & 115.96 & 17.47 & 19.32 & 12.08 .2014 & 10.2 & 119.18 & 17.82 & 19.45 \\
\hline 10.09 .2014 & 9.87 & 116.2 & 17.6 & 19.31 & 11.08 .2014 & 10.42 & 118.66 & 17.7 & 19.5 \\
\hline 09.09.2014 & 10.04 & 114.32 & 17.41 & 19.21 & 10.08 .2014 & 10.54 & 118.9 & 17.72 & 19.55 \\
\hline 08.09.2014 & 10 & 114.43 & 17.42 & 19.31 & 09.08 .2014 & 10.52 & 118.38 & 17.74 & 19.35 \\
\hline 07.09 .2014 & 10.37 & 114.91 & 17.36 & 19.42 & 08.08 .2014 & 10.75 & 119.15 & 17.8 & 19.66 \\
\hline 06.09.2014 & 10.07 & 115.08 & 17.19 & 19.46 & 07.08 .2014 & 10.65 & 118.71 & 17.54 & 19.46 \\
\hline 05.09 .2014 & 10.27 & 114.87 & 17.23 & 19.5 & 06.08 .2014 & 10.67 & 119 & 17.55 & 19.43 \\
\hline 04.09 .2014 & 10.24 & 114.09 & 17.17 & 19.49 & 05.08 .2014 & 11 & 118.52 & 17.47 & 19.15 \\
\hline 03.09 .2014 & 10.29 & 115.78 & 17.4 & 19.54 & 04.08 .2014 & 11.14 & 118 & 17.3 & 18.97 \\
\hline 02.09 .2014 & 10.23 & 115.7 & 17.41 & 19.56 & 03.08 .2014 & 11.09 & 120.04 & 17.43 & 19.21 \\
\hline 01.09 .2014 & 10.37 & 116.95 & 17.36 & 19.57 & 02.08 .2014 & 11.21 & 120.3 & 17.11 & 19.26 \\
\hline
\end{tabular}




\section{Economic evaluation of the mechanisms of attracting corporatization-focused investments}

Under such conditions any investor will begin his/her analysis using exclusively statistical indicators. This is because the number of potential recipients is not large. All other possible factors are omitted and will be considered as "noise", as random changes of different factors affecting the process of decision-taking by the investor.

One of the most common indicators used while taking decisions concerning investments into a particular enterprise is the standard deviation that is used for risk assessment (in this case, we neglect the assumption that the standard deviation can also be an indicator of the potential return on investment). In addition, let us calculate the correlation matrix of prices on shares of the four investigated companies; this will enable us to assess the degree of independence of the companies from each other and the level of competition existing between them. These calculations are presented in Tables 2, 3 .

Table 2

Correlation matrix based on the data from Table 1

\begin{tabular}{|c|c|c|c|c|}
\hline & $A$ & $B$ & $C$ & $D$ \\
\hline$A$ & 1 & -0.45437 & 0.631262 & -0.17852 \\
\hline$B$ & -0.45437 & 1 & -0.6052 & 0.677127 \\
\hline$C$ & 0.631262 & -0.6052 & 1 & -0.3501 \\
\hline$D$ & -0.17852 & 0.677127 & -0.3501 & 1 \\
\hline
\end{tabular}

Table 3

Absolute and relative standard deviations based on the data from Table 1

\begin{tabular}{|l|c|c|c|c|}
\hline & $A$ & $B$ & $C$ & $D$ \\
\hline $\begin{array}{l}\text { Absolute } \\
\text { values }\end{array}$ & 0.24496 & 1.47731 & 0.66031 & 0.148519 \\
\hline $\begin{array}{l}\text { Relative } \\
\text { values }\end{array}$ & 0.02449 & 0.012666 & 0.03939 & 0.007602 \\
\hline
\end{tabular}

* Notes: The relative value is calculated as the ratio of the standard deviation absolute value to the arithmetic mean value of the market prices on the company's shares.

As can be seen from Tables 2 and 3, especially significant is the directly proportional dependence between the shares of $\mathrm{B}, \mathrm{D}$ and $\mathrm{A}, \mathrm{C}$ companies as well as the inversely proportional dependence between the shares of companies A, B and $\mathrm{B}, \mathrm{C}$. This allows us to assume that the defined two groups of companies (B, D and $\mathrm{A}, \mathrm{C})$ can be used to create individual portfolios. This is due to the fact that the interdependence between these companies is directly proportional, so they can hardly be seen as competitors. In their turn, groups of A, B and $\mathrm{B}, \mathrm{C}$ companies cannot be taken as a basis for forming the investment portfolios as the market values of their shares are inversely proportional. The D company is the least dependent on others.

Analysis of the values of the absolute and relative standard deviations makes it possible to establish the level of risk to be assessed by potential investors. Thus, the lowest level of risk is observed for shares of D company.

Further analysis can be made in different ways. For example, we can analyze the dependence of the stock prices of the most independent company and the company with the least risk of the values of stock prices of other companies. This will make it possible to analyze the nature of the relationship that exists between these time series. Choosing the least independent and low risk company is a priority for investors planning to make direct investments. The review of the "portfolio investor" decisions is presented below.

Thus, the analysis has shown that the D company is the most attractive for direct investments. Confirmation or refutation of this assumption is possible with further analysis which will concern the definition of the nature of the relationship that exists between the stocks selected in the previous step and the shares of other companies. To demonstrate the visibility of this method let us assume that the investor is still not sure of their choice in favor of D. He decides to analyze the shares of this company and those of company $\mathrm{B}$, the risk of which is the lowest after the shares of D. A significant relationship between the dynamics of stock prices of the two companies also shows the necessity for further analysis.

Let us analyze the nature of the relationship on the basis of the following regression equation:

$$
\begin{aligned}
& p_{3}=\lambda_{0}+\lambda_{1} p_{1}+\lambda_{2} p_{2}+\lambda_{12} p_{1} p_{2}+ \\
& +\lambda_{11} p_{1}^{2}+\lambda_{22} p_{2}^{2}+\lambda_{33} p_{1}^{3}+\lambda_{44} p_{2}^{3},
\end{aligned}
$$

where: $\lambda_{0}, \lambda_{1}, \lambda_{2}, \lambda_{12}, \lambda_{11}, \lambda_{22}, \lambda_{33}, \lambda_{44}$ are coefficients of the equation; $p_{1}, p_{2}-$ values of stock prices of companies that serve as independent variables; $p_{3}$ - values of the companies prices, the parameter being researched.

Let us present the obtained equations for companies B, D (Table. 4).

As can be seen from Table 4, both companies are equally dependent on their competitors. As the obtained correlation coefficients for the two companies are practically identical, the further analysis of the dynamics of stock prices of these companies is necessary. 
Regression equations of dependencies of companies B, D share prices on the values of the stock prices of other companies

\begin{tabular}{|c|c|c|}
\hline$D(A, C)$ & $p_{3}=-1831,64+363,05 p_{1}+115,76 p_{2}+0,91 p_{1} p_{2}-36,33 p_{1}^{2}-$ & $R^{2}=0,394$ \\
\hline$B(A, C)$ & $p_{3}=-84473,84+1773,76 p_{1}^{2}+328,76 p_{1}^{3}+0,15 p_{2}^{3}$ & \\
& $+35,71 p_{2}^{2}+2,2,64 p_{1}^{3}-1,08 p_{2}^{3} p_{2}-107,26 p_{1}^{2}+$ & $R^{2}=0,396$ \\
\hline
\end{tabular}

The further analysis is possible if the studied values are presented in the same coordinate system and compared. To do this, we calculate the relative change in share prices of the two companies and re-construct the regression equation of the form (1). Let us calculate the relative change as follows:

$$
R_{i}=\frac{\left(p_{i}-p_{i-1}\right)}{\max \left(p_{i}\right)},
$$

where: $p_{i}, p_{i-1}$ are the current and the previous values of the price on a share of the company.

The calculated relative changes in stock prices are shown in Table 5.

On the basis of the data of Table 5 we can construct two dependence functions of form (1). These equations are presented in Table 6 .

Table 5

The relative changes in stock prices of companies B and D

\begin{tabular}{|c|c|c|c|c|c|}
\hline Date & $B$ & $D$ & Date & $B$ & $D$ \\
\hline 30.09 .2014 & - & - & 31.08 .2014 & 0.002156 & 0.000991 \\
\hline 29.09 .2014 & $-8.3 \mathrm{E}-05$ & 0.009906 & 30.08 .2014 & -0.00265 & -0.00991 \\
\hline 28.09 .2014 & 0.009371 & 0.00842 & 29.08 .2014 & 0.007049 & 0.005448 \\
\hline 27.09 .2014 & -0.00647 & -0.00991 & 28.08 .2014 & 0.001576 & 0.004458 \\
\hline 26.09 .2014 & 0.003151 & 0.016345 & 27.08 .2014 & -0.00572 & -0.01634 \\
\hline 25.09 .2014 & 0 & -0.00743 & 26.08 .2014 & -0.00398 & -0.00198 \\
\hline 24.09 .2014 & 0.006303 & -0.00198 & 25.08 .2014 & 0.007215 & -0.00248 \\
\hline 23.09 .2014 & -0.00207 & -0.0005 & 24.08 .2014 & -0.00788 & -0.01436 \\
\hline 22.09 .2014 & 0.005556 & -0.00297 & 23.08 .2014 & -0.00058 & 0.010896 \\
\hline 21.09 .2014 & -0.01725 & -0.00297 & 22.08 .2014 & 0.02007 & 0.005448 \\
\hline 20.09 .2014 & 0.00199 & 0.011392 & 21.08 .2014 & -0.00755 & 0.018326 \\
\hline 19.09 .2014 & -0.00357 & -0.00892 & 20.08 .2014 & -0.0044 & 0.002476 \\
\hline 18.09 .2014 & -0.00041 & 0.001981 & 19.08 .2014 & 0.003317 & 0.001486 \\
\hline 17.09 .2014 & -0.00614 & 0.000991 & 18.08 .2014 & 0.017001 & 0.015354 \\
\hline 16.09 .2014 & 0.000995 & -0.0005 & 17.08 .2014 & 0.004478 & -0.00198 \\
\hline 15.09 .2014 & -0.01219 & -0.01288 & 16.08 .2014 & 0 & 0.012878 \\
\hline 14.09 .2014 & 0.008459 & 0.009411 & 15.08 .2014 & -0.00788 & -0.03715 \\
\hline 13.09 .2014 & 0.002903 & -0.00347 & 14.08 .2014 & -0.00208 & 0.008138 \\
\hline 12.09 .2014 & -0.00282 & 0 & 13.08 .2014 & 0.000416 & -0.01475 \\
\hline 11.09 .2014 & -0.00075 & -0.00892 & 12.08 .2014 & -0.00208 & 0.007121 \\
\hline 10.09 .2014 & 0.00199 & -0.0005 & 11.08 .2014 & -0.00432 & 0.002543 \\
\hline 09.09 .2014 & -0.01559 & -0.00495 & 10.08 .2014 & 0.001995 & 0.002543 \\
\hline 08.09 .2014 & 0.000912 & 0.004953 & 09.08 .2014 & -0.00432 & -0.01017 \\
\hline 07.09 .2014 & 0.003981 & 0.005448 & 08.08 .2014 & 0.006401 & 0.015768 \\
\hline 06.09 .2014 & 0.00141 & 0.001981 & 07.08 .2014 & -0.00366 & -0.01017 \\
\hline 05.09 .2014 & -0.00174 & 0.001981 & 06.08 .2014 & 0.002411 & -0.00154 \\
\hline 04.09 .2014 & -0.00647 & -0.0005 & 05.08 .2014 & -0.00399 & -0.01441 \\
\hline 03.09 .2014 & 0.014016 & 0.002476 & 04.08 .2014 & -0.00432 & -0.00935 \\
\hline 02.09 .2014 & -0.00066 & 0.000991 & 03.08 .2014 & 0.016958 & 0.012461 \\
\hline 01.09 .2014 & 0.010367 & 0.000495 & 02.08 .2014 & 0.002161 & 0.002596 \\
\hline & & & & & \\
\hline
\end{tabular}


Table $6^{*}$

\begin{tabular}{|c|c|}
\hline$D(A, C)$ & $\Delta_{D}=-20,28+7,98 p_{1}-1,16 p_{2}+0,015 p_{1} p_{2}-0,79 p_{1}^{2}+0,061 p_{2}^{2}+0,026 p_{1}^{3}-0,0013 p_{2}^{3}$ \\
\hline$B(A, C)$ & $\Delta_{B}=15,42-1,49 p_{1}-2,13 p_{2}-0,004 p_{1} p_{2}+0,092 p_{1}^{2}-0,21 p_{2}^{2}-0,002 p_{1}^{3}-0,007 p_{2}^{3}$ \\
\hline
\end{tabular}

"Notes: $\Delta$-dependence of the values obtained from relation (2) and the values of shares of companies $A$ and $C$.

The next step is calculating the ratio changes depending on the level of stock prices of one of the two companies studied $(\mathrm{B}, \mathrm{D})$ on stock price values of other companies. This can be done by calculating the relationship between the volumes of figures formed by the functions presented in Table 6 .

Then such a relationship can be represented by the following equation:

$$
E=\frac{\iint_{T} \Delta_{D} d p_{1} d p_{2}}{\iint_{T} \Delta_{B} d p_{1} d p_{2}}, T \in\left[\min p_{1} ; \max p_{1}\right]
$$

If this value is greater than 1 , then the company whose data are above the line is more dependent on its competitors than the other of the researched companies; if it is less than 1, the company is less dependent.

Although this method is meant for helping investors choose the potential company for direct investments, it is also an economic evaluation of investments-attracting mechanisms, as it involves determining the enterprise whose investmentsattracting mechanism is most likely to attract investments, and therefore deserves the highest economic evaluation.

In our case, $E>1$, indicating a high dependence of company $\mathrm{D}$ on its competitors. Therefore, investments-attracting mechanisms used by company $\mathrm{B}$ may be regarded as having the best chance to attract direct investments. The further research into these issues may deal with developing the similar method of evaluating investmentsattracting mechanisms but for "portfolio" investors.

\section{References}

1. Manciaux S. The notion of investments: new controversies / S. Manciaux // The Journal of World Investments \& Trade. $-2008 .-P .1-3$

2. Bee J. W. $R \& D$ Investments, Exporting, and the Evolution of Firm Producticity / J. W. Bee, J. R. Mark, X. U. Daniel // American Economic Review: Paper\&Proceeding. 2008. - P. 451-452.

3. Kenneth A. F. Institutional Portfolio Flows and International Investments // A. F. Kenneth, T. Ramardorai / NBER. 2008. - P. 1, 2.
4. Lewis A. Goldenberger, MD Potential Application of Fractals and Chaos Theory to Senescence / A. Lewis, M. D. Lipsitz, L. Ary // JAMA, June 29, 2009.

5. Abboud S. Simulation of high-resolution QRS complex using a ventricular model with a fractal conduction system: effects of ischemia on highfrequency QRS potentials / S. Abboud, O. Berenfeld, D. Sadeh // Circ Res. 1991; 68:1751-1760.

6. Mandelbrot B. B. The Fractal Geometry of Nature / B. B. Mandelbrot // New York, NY: WH Freeman and Company, 1982.

7. Baumol W. J. Chaos: Significance, Mechanism and Economic Applications / W. J. Baumol, J. Benhabib // Journal of Economics Perspectives - Volume 3, Number 1. - 1989.

8. Baumol W. J. Chaos Economic Growth / W. J. Baumol, R. E. Quandt // Journal of Economic Theory, 1979, 21. - P. 421-444.

9. Philips A. W. Stabilization Policy in a Closed Economy / A. W. Philips // Economic Journal, 1954, 64. - P. 290-323.

10. Philips A. W. Stabilization Policy and the TimeForm of Lagged Responses / A. W. Philips // Economic Journal, 1957, 67. - P. 265-277.

11. Grukenheimer J. Nonlinear oscillations, dynamical system, bifurcation of vector fields / J. Grukenheimer, P. Holmes. - New York: Springer Verlag. 1983.

12. Grandmont J. M. On endogenous business cycles / J. M. Grandmont // Econometrica. - 1985. P. 995-1046.

13. Grandmont J. M. Nonlinear difference equation, bifurcation and chaos: An introduction / J. M. Grandmont // CEPREMAP Working Paper No. 8811, June 1988.

14. Arrowsmith D. K. An introduction to dynamical systems / D. K. Arrowsmith, C. M. Place. Cambridge: Cambridge University Press.

15. Boldrin M. Equilibrium models displaying endogenous fluctuations and chaos: A survey / M. Boldrin, M. Woodford // Journal of Monetary Economics, 25, 189-222.

16. Hommes C. H. Heterogeneous agent models in economics and finance. In L. Tesfatsion \& K. L. Judd (eds) / C. H. Hommes // Handbook of computational economics, vol. 2, 2006. P. 1109-1186. 


\section{N. H. Heorhiady, O. Ye. Fedorcha}

17. Medio A. Chaotic dynamics. Theory and application to economics / A. Medio. - Cambridge: Cambridge University Press, 1992.

18. Medio A. Nonlinear dynamics. A primer / A. Medio, M. Lines. - Cambridge: Cambridge University Press, 2001.

19. Day R. H. An introduction to dynamical systems and market mechanisms / R. H. Day // Complex economic dynamics, Volume 1, Cambridge: MIT Press, 1994.

20. Rosser J. B. From catastrophe to chaos: A general theory of economic discontinuitie / J. B. Rosser. Boston: Kluwer, 2000.

21. Mantegna R. N. Introduction to econphysics: correlation and complexity in finance / R. N. Mantegna, H. E. Stanley. - Cambridge, UK: Cambridge University Press, 2000.
22. Gao J. B. Assessment of long-range correlation in time series: how to avoid pitfalls / J. B. Gao, J. Hu, W. W. Tung, Y. H. Cao, N. Sarshar, V. P. Roychowdhury // Phys. Rev., 2006.

23. Michel J. B. Quantitative analysis of culture using millions of digitized books / J. B. Michel // Science, 2011. - P. 405-409.

24. Heorhyady N. H. The Entity and Types of Investment Involvement into Enterprise / N. H. Heorhyady, O. Ye. Fedorchak // Investment: practice and experience. - 2013. - № 22. - P. 6-12. (in Ukrainian).

25. Heorhyady N. H. Economic Development of Enterprise, its Entity and Types / N. H. Heorhyady, Ya. Ya. Pushak, O. Ye. Fedorchak // Scientific Commercial Journal "Business Navigator". 2013. - № 3(32). - P. 255-262. (in Ukrainian). 